\title{
Role of urinary NAG enzyme in early detection of renal impairment in cystic fibrosis patients
}

\author{
Hanan Mohsen Osman ${ }^{*}$ (D, Amal Moustafa Hagras ${ }^{1}$, Manal Michel Wilson², Ahmed M. Badr ${ }^{1}$, \\ Mona Mostafa El Falaki ${ }^{1}$ and Ahmed Saad Badawy ${ }^{1}$
}

\begin{abstract}
Background: Cystic fibrosis (CF) is the most common life-limiting autosomal recessive disease among people in the USA and Europe with increased prevalence in Egypt. Affected children are in danger of acute kidney injury and the development of chronic renal disease through exposure to multiple nephrotoxic agents. N-acetyl beta-D-glucosaminidase (NAG) is a lysosomal enzyme present in high concentrations in the proximal tubular cells, thus raising urinary NAG levels to reflect tubular dysfunction. The aim of our study is to detect the role of the urinary NAG enzyme in the early detection of renal impairment in CF patients. This cross-sectional study enrolled 40 CF patients diagnosed in the CF Clinic in Children's Hospital of Cairo University. They were age- and sex-matched to 40 healthy controls. All patients had glomerular filtration rate (GFR), serum creatinine, blood urea nitrogen (BUN), albumin/creatinine (A/C) ratio measured, urine analysis, urinary NAG enzyme using enzyme-linked immunosorbent assay (ELISA), and renal ultrasound (U/S) were done.
\end{abstract}

Results: Our study showed high levels of urinary NAG in cases with a significant difference between cases and controls ( $P$ value $<0.001$ ). There was a significant correlation between urinary NAG enzyme elevation and A/C ratio in urine, nephrotoxic drugs administration, and duration of disease ( $P$ value $=0.002,0.005,0.019)$, respectively.

Conclusion: Our study suggested that the NAG enzyme is a good early detector of renal impairment in CF patients before the conventional laboratory assays become deranged.

Keywords: Cystic fibrosis, NAG enzyme, Renal impairment, GFR

\section{Background}

Cystic fibrosis (CF) is the most common life-limiting autosomal recessive disease among people in the USA and Europe [1] with increased prevalence in Egypt due to the increased medical awareness and availability of more diagnostic tests [2].

It is a multi-system metabolic disease due to mutations in the cystic fibrosis gene, which codes for a cystic fibrosis transmembrane conductance regulator (CFTR).

\footnotetext{
*Correspondence: nana mohsen2006@yahoo.com

${ }^{1}$ Pediatric Department, Faculty of Medicine, Cairo University, Cairo, Egypt Full list of author information is available at the end of the article
}

Pulmonary disease is the most important cause of morbidity and mortality in CF [3]. As the mean life expectancy of CF patients has increased, more concern has arisen about non-pulmonary organs complication, including the kidneys [3].

CFTR is found in the kidney, mainly in the proximal and distal tubules, and its inactivation can cause low molecular weight proteinuria but its exact role and effect in CF-related kidney disease are unknown, and primary renal disease is an unusual feature, in contrast to secondary renal dysfunction that is becoming increasingly common [4]. Moreover, kidney disease is becoming increasingly common in CF in the form of acute kidney 
injury with the development of chronic kidney disease via multiple potentially nephrotoxic agents. Also, nephropathy can result from abnormalities in salt transport, colonization with pseudomonas aeruginosa, and from cystic fibrosis-related diabetes (CFRD) requiring insulin [5].

Studies have been directed towards the evaluation of urinary enzymes being a non-invasive biomarker for early diagnosis of acute renal injury also they indicate the site of primary tubular damage because of their localization [6]. N-acetyl beta-D-glucosaminidase (NAG) is a lysosomal enzyme present in high concentrations in the proximal tubular cells. Its molecular weight does not permit glomerular filtration, and thus raised urinary NAG levels to reflect tubular dysfunction. Elevation of urinary NAG enzyme has been reported in cystic fibrosis patients with renal impairment indicating its importance in early detection of renal impairment in CF patients [7].

Our study aims to early detect renal impairment in cystic fibrosis patients by assessing the level of urinary $\mathrm{N}$-acetyl beta-D-glucosaminidase (NAGase) enzyme.

\section{Patients and methods \\ Study design}

This cross-sectional study included 40 patients with cystic fibrosis (2-12 years) following in the Cystic Fibrosis clinic in Children's hospital, Cairo University, Egypt. Children were already diagnosed based on clinical presentation (chronic lung disease, steatorrhea, and failure to thrive) confirmed by a positive sweat chloride test. Patients presenting in acute exacerbation were excluded from our study to eliminate the effects of possible dehydration and sepsis on renal functions. Also, CF patients suffering of cystic fibrosis-related diabetes (CFRD) or manifested any renal affection (as hypertension or oliguria) were excluded from our study.

The severity of the disease was assessed by the Shwachman-Kulczycki score for clinical evaluation of cystic fibrosis depending on general activity, physical examination, nutritional status, and x-ray finding. Routine nephrotoxic medication in the form of inhaled aminoglycosides (inhaled gentamycin 40mg twice daily in alternative months) was prescribed for all CF cases presenting with respiratory symptoms. Forty age- and sex-matched healthy children as a control group.

\section{Ethical considerations}

The protocol for the research project was approved by the Ethics Committee of the Specialized Children's hospital, Cairo University and it conforms to the current provisions of the Helsinki declaration (ID approval: I-080215).
Informed oral consent was obtained from the parents after an explanation of the aim of the study.

\section{Method}

All the patients included in the study were coming for routine follow up, they were subjected to:

Full history taking (duration of the disease, chronic cough, recurrent pneumonia, steatorrhea, attacks of dehydration, number of hospitalization, failure to thrive, intake of nephrotoxic drugs, urine volume, and color).

Thorough clinical examination (including weight, height, blood pressure, presence of clubbing, cyanosis, signs of respiratory distress, wheeze, crepitation,...).

Investigation done was kidney function test (serum creatinine, blood urea nitrogen (BUN), glomerular filtration rate (GFR), urine analysis, albumin/creatinine $(\mathrm{A} / \mathrm{C})$ ratio in urine, urinary NAG enzyme, and renal ultrasound $(\mathrm{U} / \mathrm{S})$.

Urinary NAG enzyme was done using ELISA (enzyme-linked immunosorbent assay) technique by available kits of EIAab Science Co.Ltd (Catalog No: E0069h) which allowed in vitro quantitative determination in urine. The micro titer plate provided in this kit has been pre-coated with an antibody specific to NAG. Standards or samples were then added to the appropriate micro titer plate wells with a biotin-conjugated polyclonal antibody preparation specific for NAG. The concentration of NAG in the samples was then determined by comparing the optical density of the samples to the standard curve. The Detection Range: 1.56-100 $\mathrm{U} / \mathrm{L}$.

The glomerular filtration rate was estimated by Schwarz formula $(40$ "height $(\mathrm{cm}) /$ serum creatinine $(\mathrm{mmol} / \mathrm{l}))$.

The urine samples were collected randomly in sterile cups, for urine analysis and albumin/creatinine ratio calculation by dividing albumin concentration in milligrams by creatinine concentration in grams.

Renal U/S was done to assess the renal parenchymal thickness, echogenicity, and kidney size.

\section{Statistical methods}

Data were coded and entered using the statistical package SPSS version 22. Data was summarized using mean, standard deviation, median, minimum and maximum for quantitative variables and frequencies (number of cases) and relative frequencies (percentages) for categorical variables. Comparisons between categories were done using unpaired $t$ test in normally distributed quantitative variables while non-parametrical Mann-Whitney test was used for non-normally distributed quantitative variables. 
Correlations between quantitative variables were done using Pearson's correlation coefficient. $P$ values less than 0.05 were considered as statistically significant.

\section{Results}

The mean (SD) age of the study population was 5.82 years $( \pm 2.49)$ whereas the mean $(\mathrm{SD})$ age at first presentation was 10.95 months $( \pm 17.40)$. Twenty-four patients $(60 \%)$ were males and 16 were females $(40 \%)$. Baseline data of the studied population are illustrated in (Table 1).

The distribution of symptoms and signs among the cases were chronic cough and recurrent pneumonia as the main respiratory symptoms in $87.5 \%$, steatorrhea in $100 \%$ of cases and failure to thrive in $92.5 \%$. And according to the Shwachman-Kulczycki score for severity assessment, $24(60 \%)$ of our patients were of mild severity and $14(40 \%)$ were of moderate severity, as shown in Table 2.

Among all cases, 33 patients (82.5\%) received nephrotoxic medications in the form of inhaled aminoglycosides (inhaled gentamycin 40mg twice daily in alternative months) with mean duration of intake $28.97 \pm 12$ months (range 6-54 months).

Both calculation of GFR and recording albumin/creatinine $(\mathrm{A} / \mathrm{C})$ ratio indicate abnormal GFR and $\mathrm{A} / \mathrm{C}$ ratio in $35.0 \%$ and $17.5 \%$ of cases, respectively, with mean GFR $79.71 \pm 9.61 \mathrm{ml} / \mathrm{min} / 1.73 \mathrm{~m}^{2}$ (range $60-90 \mathrm{ml} /$ $\mathrm{min} / 1.73 \mathrm{~m}^{2}$ ) and mean $\mathrm{A} / \mathrm{C}$ ratio $32.43 \pm 2.7 \mathrm{mg} / \mathrm{g}$ (range $30.5-38.4 \mathrm{mg} / \mathrm{g}$ ).

While mean GFR and mean $\mathrm{A} / \mathrm{C}$ ratio for all cases was $116.18 \pm 42.2 \mathrm{ml} / \mathrm{min} / 1.73 \mathrm{~m}^{2}$ (range $60-262 \mathrm{ml} /$ $\mathrm{min} / 1.73 \mathrm{~m}^{2}$ ) and $20 \pm 7.76 \mathrm{mg} / \mathrm{g}$ (range $10-38.4 \mathrm{mg} / \mathrm{g}$ ), respectively, as shown in Table 3. But both GFR and A/C ratio did not show significant correlation with either the severity of disease ( $p$ value: 0.051, 0.521,

Table 1 Demographic data of the study population

\begin{tabular}{lll}
\hline Variables & $\mathbf{N = 4 0 ( 1 0 0 \% )}$ & Median (Max-Min) \\
\hline Age in years & $6(12-2.5)$ \\
Age of presentation in months & $5(72-1.0)$ \\
Duration of disease in months & $56(12-108)$ \\
$\begin{array}{l}\text { Duration of use of nephrotoxic } \\
\text { drugs in months }\end{array}$ & $28(6-54)$ \\
Residence & \\
$\quad$ Urban & \\
$\quad$ Rural & $19(47.5 \%)$ \\
Sex & $21(52.5 \%)$ \\
$\quad$ Male & \\
$\quad$ Female & $24(60 \%)$ \\
Positive consanguinity & $16(40 \%)$ \\
Positive family history with CF & $18(45 \%)$ \\
\hline
\end{tabular}

Table 2 Distribution of symptoms and signs among the cases

\begin{tabular}{lll}
\hline Variable & Number & $\%$ \\
\hline Chronic cough & 35 & 87.5 \\
Recurrent pneumonia & 35 & 87.5 \\
Recurrent sinusitis & 21 & 52.5 \\
Steatorrhea & 40 & 100 \\
Cholestatic jaundice & 10 & 25 \\
Clubbing & 18 & 45 \\
Failure to thrive & 37 & 92.5 \\
BMI & & \\
$\quad$ Normal 18.5-25 & 3 & 7.5 \\
$\quad$ Underweight ${ }^{<} 18.5$ & 37 & 92.5 \\
Severity & & \\
$\quad$ Mild & 24 & 60 \\
$\quad$ moderate & 16 & 40 \\
\hline
\end{tabular}

respectively), its duration ( $p$ value: $0.838,0.092$, respectively), or intake of nephrotoxic medication ( $p$ value: $0.169,0.119$, respectively).

Serum urea and creatinine done for all cases were normal with a mean of $20.52 \mathrm{mg} / \mathrm{dl}$ and $0.45 \mathrm{mg} / \mathrm{dl}$, respectively. These values are all shown in Table 3.

Urine analysis and renal U/S studies were normal in $95 \%$ and $97.5 \%$ of cases, respectively, while albuminuria and grade 1 echogenicity were $5 \%$ and $2.5 \%$ of cases, respectively.

On studying the urinary NAG enzyme level, there were high levels of urinary NAG ( $\geq 100 \mathrm{U} / \mathrm{L})$ in 31cases (77.5\%) with a significant difference between cases and control ( $p$ value $\left.{ }^{<} 0.001\right)$ as in Fig. 1, there was a significant correlation with duration of the disease in cases $(p$ value 0.019$)$ as illustrated in Fig. 2 and with $\mathrm{A} / \mathrm{C}$ ratio in urine $(P$ value $=0.002)$. On comparing the NAG enzyme level with severity of disease a statistically significant difference was found ( $p$ value:0.001) as illustrated in Fig. 3.

Urinary NAG enzyme level showed a statistically significant difference in $\mathrm{CF}$ patients with a positive intake of nephrotoxic medication (inhaled aminoglycosides) to those with negative intake $(P$ value $=0.005)$ Also, there was a significant correlation with the duration

Table 3 Values of GFR, A/C ratio in urine, serum urea, and creatinine among cases

\begin{tabular}{llllll}
\hline & Mean & SD & Min & Max & Normal \\
\hline GFR ml/min/1.73m² & 116.18 & 42.20 & 60.00 & 262.00 & ${ }^{>} 90$ \\
A/C ratio & 20.00 & 7.76 & 10.00 & 38.40 & ${ }^{<} 30$ \\
Serum urea & 20.52 & 7.49 & 7.00 & 43.00 & $<45$ \\
Serum creatinine & 0.45 & 0.14 & 0.20 & 0.80 & $<1.0$ \\
\hline
\end{tabular}

GFR glomerular filtration rate, $A / C$ ratio albumin/creatinine ratio 


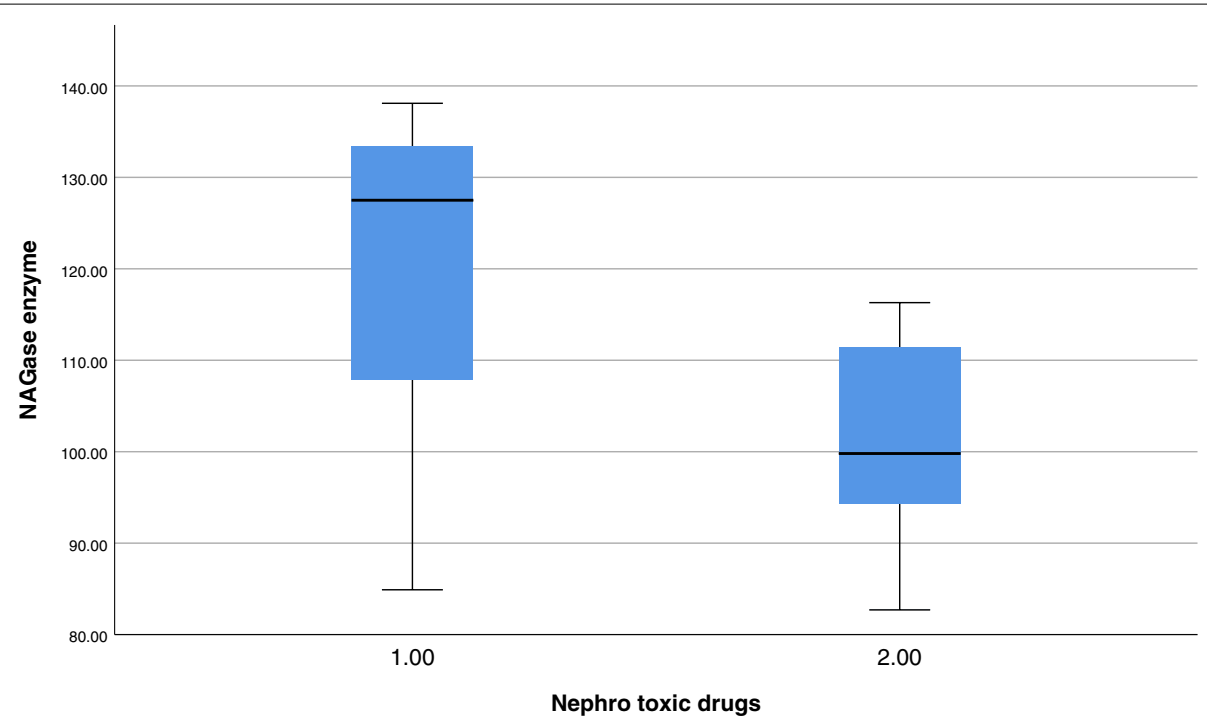

Fig. 1 Comparison between NAG enzyme in case and control

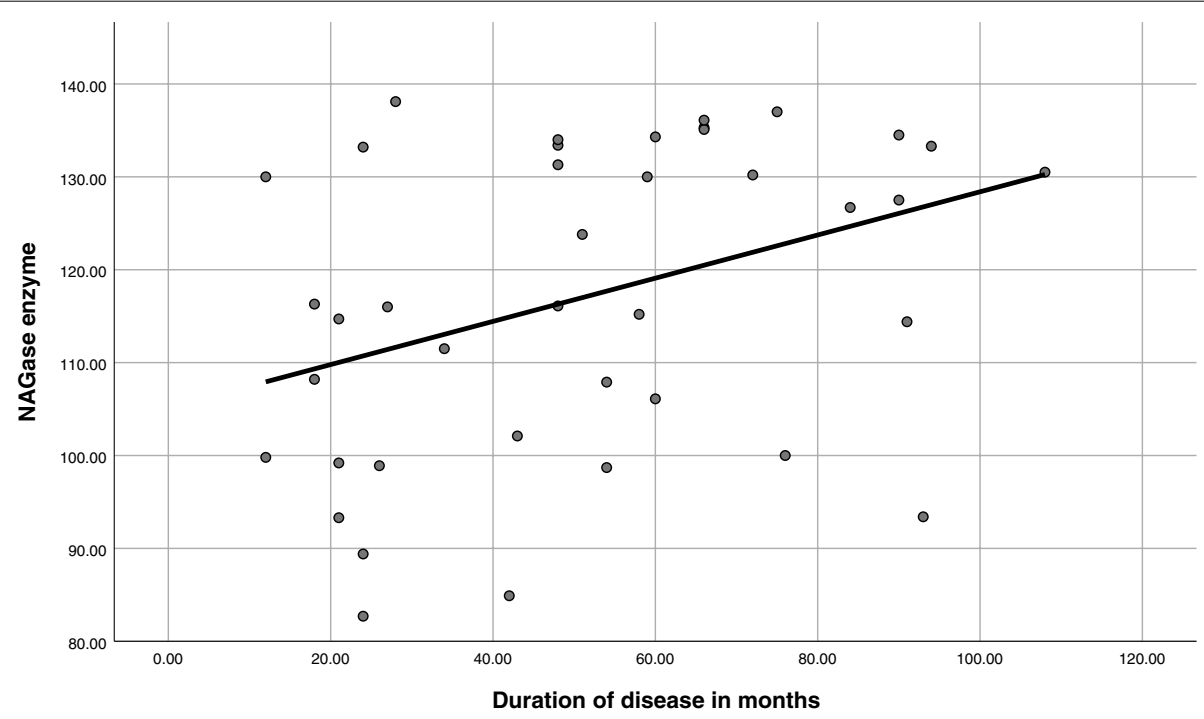

Fig. 2 Correlation between NAG enzyme level and the duration of the disease in cases $(P$ value $=0.019)$

of nephrotoxic medications intake $(P$ value $=0.008)$ shown in Table 4.

But the level of urinary NAG enzyme indicates an insignificant correlation with the number of hospitalization, GFR, serum urea, creatinine, and BMI with $P$ value $=0.496,0.377,0.472,0.610$, and 0.431 , respectively.

In our study, urinary NAG enzyme showed to have a role as an early detector of renal impairment while other tests like estimation of GFR and renal function test show a minor role in early diagnosis of renal impairment in CF cases.

\section{Discussion}

The main objective of our study was to detect early renal impairment in our CF patients by comparing the usual renal assessment through kidney function tests (urea, creatinine) GFR, A/C ratio, urine analysis, renal $\mathrm{u} / \mathrm{s}$ to urinary NAG enzyme level.

As CFTR expression and function have been demonstrated in the kidney, abnormalities in renal tubular function along with an increased risk of renal injury due to a propensity for dehydration are both well described in CF. In addition, the need to use potentially nephrotoxic 


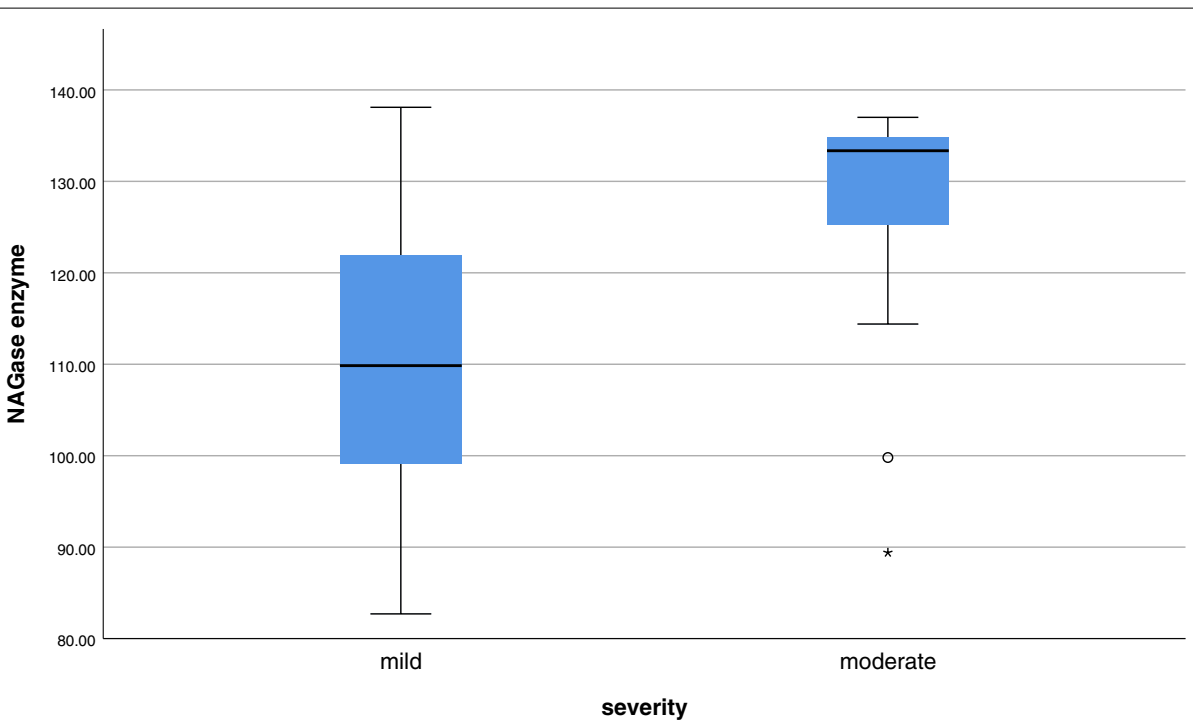

Fig. 3 Comparison between NAGase enzyme level and severity of disease ( $p$ value $=0.001$ )

Table 4 Correlation between NAGase enzyme and duration of nephrotoxic drugs intake

\begin{tabular}{lll}
\hline NAGase enzyme & $\begin{array}{l}\text { Correlation coef- } \\
\text { nephrotoxic drugs in } \\
\text { the month }\end{array}$ \\
\hline $\begin{array}{l}\text { ficient } \\
\text { v value }\end{array}$ & 0.411 \\
& $N$ & 0.008 \\
& 40 \\
\hline
\end{tabular}

$P<0.05$ is considered statistically significant

antibiotics or anti-rejection drugs (post lung transplantation) may lead to acute or chronic renal injury. This raises concerns regarding renal dysfunction in the CF population [3].

This study shows a significant elevation of urinary NAG enzyme level in CF cases compared to the healthy control group. On the contrary, the usual kidney function tests (serum urea and creatinine) were normal in all cases. While estimated GFR and recorded A/C ratio were only abnormal in $35.0 \%$ and $17.5 \%$, respectively, of cases.

This goes in line with the study done by Nazareth and Walshaw, 2013 which shows that GFR is also insensitive in the detection of early renal dysfunction as up to $30 \%$ of nephrons can cease to function before GFR alters, since the remainder compensates by increasing their filtration rate. It is only with a further loss of renal tissue that GFR will reduce [6]. The glomerular filtration rate though estimated by different formulae that are simple to use in daily practice but none has been formally validated in CF [8] due to the possibility of overestimation of these formulae to the GFR in children with CF because they are not reliable when the serum creatinine is unstable [9], as many of CF patients are in a hypermetabolic state have diminished muscle mass, and have limited exercise capacity, all of which can influence creatinine production. In addition, measurement of GFR may lead to variability or bias depending on the conditions of each patient (hydration status, protein intake) [3].

The same was observed in measuring serum creatinine in our patients as $100 \%$ had normal serum creatinine levels; this goes in correlation with a study done by Boer et al., 2010, which showed that serum creatinine levels can vary widely with age, gender, muscle mass, muscle metabolism, medications, and hydration status [10].

Hence recently, attention has been directed towards the evaluation of urinary enzymes as non-invasive biomarkers of renal tubular damage that is useful in the early diagnosis of acute renal injury before conventional laboratory assays become deranged [11-13], and they reflect sub-clinical toxicity. They may also indicate the site of primary tubular damage because of their localization in tubular lysosomes ( $\mathrm{N}$-acetyl- $\beta$ - $\mathrm{D}$ glucose-aminidase [NAG]) and the brush border (alanine amino-peptidase [AAP]) [14, 15].

$\mathrm{N}$-Acetyl- $\beta$-Dglucosaminidase is a lysosomal enzyme that leaks into urine which is mainly originated from the proximal tubular cells. This enzyme is defined as being more specific and sensitive to renal tubular injury than creatinine especially with its isoenzymes and when combined with other renal biomarkers, for example, 
Neutrophil gelatinase-associated lipocalin (NGAL) and Kim-1 [16].

In our study, there was a significant elevation of urinary NAG levels in the case group than control group ( $P$ value $<0.001$ ). This also was reported in a study of Liangos et al., 2007, where the urinary NAG enzyme has a high sensitivity for acute kidney injury (AKI) [15].

In addition, there was a positive correlation of urinary NAG levels with the duration of the disease and its severity with $P$ value 0.019 and 0.001 , respectively. This also was reported in a study by Glass et al., 2005, in which the correlation between urinary NAG enzyme elevation and duration of disease in CF children was significant [17].

Aminoglycosides target the lysosomal system within the proximal tubule. The drug initially binds to the brush border membranes and is then transferred to the tubular cell lysosomes, which may subsequently leak and rupture. Advanced toxicity is characterized by tubular cell necrosis and eventually renal failure [18].

Our study reported a statistically significant elevation of urinary NAG enzyme level in CF patients with positive intake of nephrotoxic medication to those with negative intake $(P$ value $=0.005)$ Also, there was a significant correlation of urinary NAG enzyme with the duration of nephrotoxic medications intake $(P$ value $=0.008)$.

Few previous studies assessed urinary NAG excretion in patients with CF during inhaled aminoglycoside treatment. Steinkamp et al. reported a significant increase in mean urinary NAG excretion in 10 patients treated with intravenous tobramycin, while inhaled tobramycin produced no alteration in urinary NAG activity [14], on the other side Ring et al. demonstrated in those patients receiving gentamicin inhalation a positive correlation between urinary NAG and the cumulative dose of nebulized gentamicin [19].

\section{Conclusion}

This study proves the significant role of measuring urinary NAG enzyme in patients with cystic fibrosis as a noninvasive easy biomarker that early detects and identifies patients at risk of developing renal disease. Especially that better knowledge of renal involvement in patients with CF is mandatory, as continuous improvement in the treatment of these patients translates into a significant increase in life expectancy and avoids increased risk for developing a renal disease related to cumulative drug toxicity or to complications of chronic infections (AA amyloidosis) or organ failure (CF-related diabetes).

\section{Abbreviations}

CF: Cystic fibrosis; CFTR: Cystic fibrosis transmembrane conductance regulator; CFRD: Cystic fibrosis-related diabetes; NAG: N-acetyl beta-D-glucosaminidase.
Acknowledgements

Not applicable

\section{Authors' contributions}

Hanan Mohsen Osman: contributed in patients' collection, analysis of the results, and writing the discussion. Amal Moustafa Hagras: contributed in the writing and the revision of the review and the results. Manal Michel Wilson: responsible for laboratory techniques needed in the research. Ahmed M. Badr: responsible for the abdominal U/S needed in the research. Mona Mostafa El Falaki: contributed in the final revision of the whole research. Ahmed Saad Badawy: contributed in patients' collection. The authors read and approved the final manuscript.

\section{Funding}

Our study was self-funded.

\section{Availability of data and materials}

The datasets used and/or analyzed during the current study are available from the corresponding author on reasonable request.

\section{Declarations}

\section{Ethics approval and consent to participate}

The protocol for the research project was approved by the Ethics Committee of the Specialized Children's hospital, Cairo University and it conforms to the current provisions of the Helsinki declaration (ID approval: I-080215). Informed oral consent was obtained from the parents after an explanation of the aim of the study.

\section{Consent for publication}

It is not applicable as our study did not contain any individual person's data in any form.

\section{Competing interests}

The authors declare that they have no competing interests.

\section{Author details}

${ }^{1}$ Pediatric Department, Faculty of Medicine, Cairo University, Cairo, Egypt. ${ }^{2}$ Clinical and Chemical Pathology Department, Faculty of Medicine, Cairo University, Cairo, Egypt.

Received: 24 November 2021 Accepted: 15 January 2022

Published online: 21 February 2022

References

1. Jozwik CE, Pollard HB, Srivastava M, Eidelman O, Fan Q, Darling TN, Zeitlin PL (2012) Antibody microarrays. Analysis of cystic fibrosis. Methods Mol Biol 823:179-200

2. El-Falaki M, Shahin W, El-Basha N, Alia A, Mehaney D, El-Attar M (2013) Profile of cystic fibrosis in a single referral center in Egypt. J Adv Res 5(5):563-568

3. Prestidge C, Chilvers MA, George A, Davidson F, Cho E, McMahon V, Colin TW (2011) Renal function in pediatric cystic fibrosis patients in the first decade of life. Pediatr Nephrol 26:605-612

4. Jouret F, Bernard A, Hermans C, Dom G, Terryn S, Leal T, Lebecque P, Cassiman JJ, Scholte BJ, de Jonge HR, Courtoy PJ, Devuyst O (2007) Cystic fibrosis is associated with a defect in apical receptor-mediated endocytosis in mouse and human kidney. J Am Soc Nephrol 18:707-718

5. Bertram J, Douglas-Denton R, Diouf B, Hughson M, Hoy W (2011) Human nephron number: implications for health and disease. Pediatr Nephrol 26:1529-1533

6. Nazareth D, Walshaw M (2013) A review of renal disease in cystic fibrosis. Cyst Fibros 12(4):309-317

7. Etherington C, Bosomworth M, Clifton I, Peckham DG, Conway SP (2007) Measurement of urinary $\mathrm{N}$-acetyl-b- D -glucosaminidase in adult patients with cystic fibrosis: before, during and after treatment with intravenous antibiotics. J Cyst Fibros 6:67-73 
8. Al-Aloul M, Jackson M, Bell G, Ledson M, Walshaw M (2007) Comparison of methods of assessment of renal function in cystic fibrosis (CF) patients. J Cyst Fibros 6:41-47

9. Selvadurai HC, Allen J, Sachinwalla T, Macauley J, Blimkie CJ, Van Asperen PP (2003) Muscle function and resting energy expenditure in female athletes with cystic fibrosis. Am J Respir Crit Care Med 168:1476-1480

10. Boer DP, de Rijke YB, Hop WC, Cransberg K, Dorresteijn EM (2010) Reference values for serum creatinine in children younger than 1 year of age. Pediatr Nephrol 25(10):2107-2113

11. Sethi K, Diamond LH (1981) Aminoglycoside nephrotoxicity and its predictability. Nephron 27:265-270

12. Mondorf AW (1982) Urinary enzymes. Characterization and diagnostic use. MMW Munch Med Wochenschr 124:230

13. Trollfors B, Wahl M, Alestig K (1980) Co-trimoxazole, creatinine and renal function. J Infect 2:221-226

14. Steinkamp G, Lutge M, Wurster U, Schulz-Baldes JG, Grone HJ, Ehrich JH (1986) Renal function in cystic fibrosis: proteinuria and enzymuria before and after tobramycin therapy. Eur J Pediatr 145:526-531

15. Liangos $\mathrm{O}$, Perianayagam MC, Vaidya VS, Han WK, Wald R, Tighiouart $H$, MacKinnon RW, Li L, Balakrishnan VS, Pereira BJ, Bonventre JV, Jaber BL (2007) Urinary N-acetyl-beta-(D)-glucosaminidase activity and kidney injury molecule-1 level are associated with adverse outcomes in acute renal failure. J Am Soc Nephrol 18(3):904-912

16. Patel VB, Preedy VR (2016) Biomarkers in Kidney Disease: Methods, Discoveries and Applications. Springer, Dordrecht

17. Glass S, Plant ND, Spencer DA (2005) The effects of intravenous tobramycin on renal tubular function in children with cystic fibrosis. J Cyst Fibros 4:221-225

18. Tune BM, Reznik VM, Mendoza SA (1994) Renal complications of drug therapy. In: Holliday MA, Barratt TM, Avner ED (eds) Pediatric nephrology. Williams \& Wilkins, Baltimore, pp 1212-1226

19. Ring E, Eber E, Erwa W, Zach MS (1998) Urinary N-acetyl-beta dglucosaminidase activity in patients with cystic fibrosis on long-term gentamicin inhalation. Arch Dis Child 78:540-543

\section{Publisher's Note}

Springer Nature remains neutral with regard to jurisdictional claims in published maps and institutional affiliations.

\section{Submit your manuscript to a SpringerOpen ${ }^{\circ}$ journal and benefit from:}

- Convenient online submission

- Rigorous peer review

- Open access: articles freely available online

- High visibility within the field

- Retaining the copyright to your article

Submit your next manuscript at $\gg$ springeropen.com 